\title{
A propósito de la semiótica y las ciencias humanas (Comentario a la exposición de Desiderio Blanco)
}

\author{
ÓsCar QueZADA MACHIAVELLO
}

\section{Consideración previa}

Desiderio Blanco ha presentado una ponencia al Seminario-Taller de Investigación «Fernando Tola Mendoza» organizado por la Facultad de Letras y Ciencias Humanas de la Universidad Nacional Mayor de San Marcos titulada Semiótica y Ciencias Humanas en la que reflexiona en torno a esa relación en la perspectiva de la interdisciplinariedad. En un primer momento, da cuenta de la confluencia de disciplinas en la que nace la semiótica moderna y explica someramente las dos direcciones que sigue (semiología, que se ocupa del signo; y semiótica, que se ocupa de la significación en discurso). Asume luego la opción de la semiótica tal como es caracterizada a partir de la obra de A. J. Greimas. El método semiótico consiste, entonces, en observar de dos modos cómo se genera la significación en el discurso: sea que se trate de la significación en el discurso terminado o, más bien, en el discurso en acto. El primer modo se vincula con la etapa estructuralista y generativa de la semiótica (que se resume del modo más económico en el modelo del recorrido generativo). El segundo modo, sin abandonar el anterior, quiere rendir cuenta del discurso viviente, y no solamente de sus estructuras formales desprendidas de su enunciación. Desde ese momento, a los paradigmas estructural y generativo se suma el paradigma tensivo y sensible: en consecuencia, prevalecerá el punto de vista de la praxis enunciativa en cuanto que «aventaja», sin reemplazarlo, al del recorrido generativo.

En un segundo momento, Blanco identifica de modo muy general los aportes de la linguística, de las ciencias cognitivas, de las corrientes formalistas, de la fenomenología y de la filosofía. Para terminar de caracterizar la problemática de la interdisciplinariedad, profundiza el concepto-modelo de praxis enunciativa que condensa de modo más económico la elaboración teórica actual.

Ante el pedido que se me ha hecho de comentar esa ponencia, he optado ya no por pensar las ciencias humanas desde el "proyecto científico» semiótico, puesto que Desiderio Blanco lo ha hecho magistralmente en pocas páginas. He decidido, pues, invertir la orientación y reflexionar en torno al proyecto semiótico desde el «mapa» epistemológico de las ciencias humanas trazado por Foucault, quizá el más célebre y difundido de nuestro tiempo. 


\section{Triedro de Foucault y «proyecto semiótico»}

Las ciencias humanas, en términos de Foucault (1966), son un conjunto de discursos que toman por objeto al hombre en lo que tiene de empírico. Desiderio Blanco, a su vez, recuerda que Greimas reflexionaba sobre "el estatuto semiótico" de ese conjunto de discursos (restringido convencionalmente, por cierto, a las llamadas «ciencias sociales»). Quizá las preocupaciones actuales nos han llevado a invertir estos términos para pensar, más bien, en «el estatuto científico» de la semiótica, en la medida en que esta disciplina, al menos en su vertiente estructural, generativa y ahora tensiva, ha aspirado a constituirse sin ambages en algo así como una matemática de las ciencias humanas.

Foucault nos recuerda que el campo epistemológico que recorren las "ciencias humanas» no ha sido prescrito de antemano: ninguna filosofía, ninguna opción política o moral, ninguna ciencia empírica, ninguna observación del cuerpo humano, ningún análisis de la sensación, de la imaginación o de las pasiones ha encontrado jamás, en los siglos XVII y XVIII, algo así como el hombre, pues el hombre no existía (como tampoco la vida, el trabajo y el lenguaje) y las «ciencias humanas» aparecieron cuando bajo el efecto de algún racionalismo que ejercía presión (en el caso de la semiótica el más evidente es el racionalismo crítico de Kant), de algún problema científico no resuelto, de algún interés práctico, se decidió pasar al hombre al lado de los objetos científicos -en cuyo número no se ha probado aún de manera absoluta que pueda incluírsele-; en suma, cuando se decidió que «el hombre» se constituyese como aquello que hay que pensar y aquello que hay que saber. Cada una de las «ciencias humanas» surge históricamente con ocasión de un problema, de una exigencia, de un obstáculo teórico o práctico... pero el hecho desnudo de que por primera vez desde que existen seres humanos y viven en sociedad, el hombre aislado o en grupo se haya convertido en objeto de la ciencia, es un acontecimiento en el orden del saber. Acontecimiento que se produjo en una redistribución general de la episteme moderna: era muy necesario en estas condiciones que el conocimiento del hombre apareciera, en su dirección científica, como contemporáneo y del mismo género que la biología, la economía y la filología, a tal grado que se vio en él, muy naturalmente, uno de los progresos decisivos de la racionalidad empírica.

La episteme moderna aparece como un espacio voluminoso y abierto de acuerdo con tres dimensiones. Sobre una de ellas se colocarín las ciencias matemáticas y físicas, para las cuales el orden es siempre un encadenamiento deductivo y lineal de proposiciones evidentes o comprobadas; en otra dimensión estarían las ciencias (como las del lenguaje, de la vida, de la producción y de la distribución de las riquezas) que proceden a poner en relación elementos discontinuos pero análogos, 
de tal modo que pueden establecer entre ellos relaciones causales y constantes de estructura. Estas dos primeras dimensiones definen entre sí un plan común: aquel que puede aparecer, según el sentido en el que se le recorra, como campo de aplicación de las matemáticas a esas ciencias empíricas o como dominio de lo 'matematizable' en la linguística, la biología y la economía. Desiderio Blanco remite aquí, en orden a la historia de la semiótica, a Shannon y Weaver pero cabe recordar también el decisivo aporte de las matemáticas de las catástrofes de René Thom y sus desarrollos actuales a cargo de Jean Petitot.

La tercera dimensión es la reflexión filosófica que se desarrolla como pensamiento de lo Mismo; con la dimensión de la biología, de la economía y de la linguiística dibuja un plan común: allí aparecen diversas filosofías de la vida, del hombre enajenado, de las formas simbólicas (cuando se trasponen a la filosofía los conceptos y los dominios nacidos en diferentes dominios empíricos tal como lo hace paradigmáticamente Cassirer); pero allí aparecieron también, si se interroga desde un punto de vista radicalmente filosófico el fundamento de estas 'empiricidades', las ontologías regionales que trataron de definir lo que son, en su ser propio, la vida, el trabajo y el lenguaje; por último, la dimensión filosófica definió con la de las disciplinas matemáticas un plan común: el de la formalización del pensamiento.

Ahora bien, las «ciencias humanas» están excluidas de este triedro epistemológico ya que no se las puede encontrar en ninguna de las dimensiones ni en la superficie de los planes así dibujados. Pero, a la vez, puede decirse que están incluidas en él, ya que es en el intersticio de esos saberes, más exactamente en el volumen definido por sus tres dimensiones donde encuentran su lugar. Esta situación las pone en relación con todas las otras formas de saber: tienen el proyecto de darse o de utilizar, en uno u otro nivel, una formalización matemática (ya hemos mencionado en el campo de la semiótica a Petitot); proceden según los modelos tomados de la biología (Thomas Sebeok, siguiendo las huellas de Von Uexkull es un claro ejemplo con su definición de la semiótica como «ciencia de la vida»), de la economía (los años setenta representan esta tendencia: Baudrillard, Ponzio, Verón, Pecheux, Rossi Landi, por citar algunos hitos) y de las ciencias del lenguaje (Hjelmslev, Barthes, Todorov, Metz, Genette, Greimas). Además, aún cuando muchas no estén concientes de ello, se dirigen en última instancia a ese modo de ser del hombre que la filosofía trata de pensar en el nivel de la finitud radical: la existencia humana viene arrojada, o entregada, al ente. De ahí se sigue su nihilidad y finitud. Ninguna existencia viene al existir en virtud de su propia resolución o decisión; asimismo, ninguna existencia, mientras existe puede ver por qué tendría necesariamente que existir, es decir, por qué no podría no existir. Antes bien, cada existencia puede también no ser, entiende que el no-existir-ya-más es una posibilidad; se mueve, pues al filo del no. Este 
"carácter de no» pertenece a la esencia de su ser, es su fuerza peculiar (en esa perspectiva, los semióticos han dialogado y discutido, como Eco y otros, con Heidegger, con Ricoeur, o con Gadamer) y algunos, como Peirce, son ante todo filósofos.

Pues bien, quizás es esta repartición nebulosa en un espacio de tres dimensiones lo que hace que las ciencias humanas sean tan difíciles de situar, tan irreductiblemente precarias en lo que respecta a su localización en el dominio epistemológico; lo que las hace aparecer a la vez como peligrosas y en peligro. Lo que explica la dificultad de las ciencias humanas, su precariedad, su incertidumbre como ciencias, su peligrosa familiaridad con la filosofía, su mal definido apoyo en otros dominios del saber, su carácter siempre secundario y derivado, pero también su pretensión a lo universal... es la complejidad de la configuración epistemológica en que se encuentran colocadas, su relación constante con esas tres dimensiones en las que buscan su espacio.

Por lo que vemos, el drama epistemológico del "proyecto semiótico», al menos en su vertiente estructural, generativa y tensiva, puede parecerse bastante al trazado por Foucault en su célebre triedro de las "ciencias humanas». La pregunta cae por su propio peso: ¿la semiótica estaría incluida entonces dentro de las ciencias humanas o acaso «se saldría» de su ámbito? Dejémosla abierta.

\section{La forma de las ciencias humanas y la cuestión de la significación}

Continuemos entonces por la senda de Foucault: entre las tres dimensiones que abren a las ciencias humanas su propio espacio y les procuran el volumen del que forman parte, la de las matemáticas es quizá la menos problemática; en todo caso, las ciencias humanas mantienen con ellas sus relaciones más claras, más serenas y, en cierta forma, más transparentes; tanto que el recurrir a las matemáticas, en una u otra forma, ha sido siempre la manera más simple de prestar al saber positivo acerca del hombre un estilo, una forma, una justificación científica. En cambio, las dificultades más fundamentales, aquellas que permiten definir mejor lo que son las ciencias humanas, se alojan por el lado de las otras dos dimensiones del saber: aquella en la que se despliega la analítica de la finitud y aquella a lo largo de la cual se reparten las ciencias empíricas que tienen por objeto a la vida, al trabajo $\mathrm{y}$ al lenguaje.

En efecto, las ciencias humanas se dirigen al hombre en la medida en que vive, en que produce y en que habla. En cuanto ser vivo crece, tiene funciones y necesidades, ve abrirse un espacio en el que anuda en sí mismo las coordenadas móviles; de manera general, su existencia corporal lo entrecruza de un cabo a otro con lo vivo; al producir los objetos y los útiles, al cambiar aquello de lo que necesita, 
al organizar toda una red de circulación a lo largo de la cual corre aquello que puede consumir y en la que él mismo está definido como un relevo, aparece su existencia inmediatamente enmarañada con otras; por último, dado que tiene un lenguaje, puede constituirse todo un universo simbólico en el interior del cual tiene relación con su pasado, con las cosas, con otro, a partir del cual puede construir también algo así como un saber de sí mismo.

Cabe aquí apuntar que, cuando explica la semiótica en los términos de Greimas, Blanco pone de relieve el hecho de que la significación se define como fenómeno translingüístico. Está hecha con el lenguaje (o, más bien, de lenguaje), pero no se reduce al lenguaje; su materia es la vida entera, la experiencia vital transformada en la producción discursiva.

De ese modo, la caracterización de la significación como fenómeno translingüístico resulta decisiva, pues, en la explicación que de inmediato se despliega, aparece como fenómeno transversal, es decir, como algo que atraviesa «de cabo a rabo» el mapa empírico trazado por Foucault a propósito de lo humano: la significación «está hecha de lenguaje» (hombre como ser que habla), su materia es la vida entera (hombre como ser que vive), la experiencia vital transformada en la producción discursiva (hombre como ser que trabaja y produce). El fenómeno de la significación se convierte así en una clave articulatoria contundente del campo de las ciencias humanas que quizá Foucault, obnubilado u obsesionado por la cuestión de la representación, no alcanzó a percibir, al menos con la concentrada precisión que Blanco muestra.

Siempre para Foucault, es posible fijar el sitio de las ciencias del hombre en la vecindad, en las fronteras inmediatas y a todo lo largo de esas ciencias en las que se trata de la vida, del trabajo y del lenguaje. Ciencias que se formaron precisamente en la época en que, por vez primera, se ofrece el hombre a la posibilidad de un saber positivo. Sin embargo, señala que ni la biología, ni la economía, ni la filología, debían ser consideradas como las primeras ciencias humanas ni como las más fundamentales. Sin duda, si se deja de lado la tesis de la representación, el planteamiento de Foucault puede parecer ambiguo porque primero caracteriza a la biología, la economía y la filología (sutilmente desplazada después por la linguí́stica) como «ciencias empíricas» y luego resulta que no son ni las primeras ni las más fundamentales "ciencias humanas». La vida, el trabajo y el lenguaje aparecerán como superficies positivas, empíricas, de proyección de lo humano cuyas «ciencias» no serían y serían «humanas».

Esa aparente contradicción empieza a diluirse cuando Foucault plantea que, de modo muy general, el hombre no es para las ciencias humanas, ese ser vivo que tiene una forma muy particular (una fisiología muy especial y una autonomía casi única); es ese ser vivo que, desde el interior de la vida a la cual pertenece por 
completo y por la cual está atravesado todo su ser, constituye representaciones gracias a las cuales vive y a partir de las cuales posee esta extraña capacidad de poder representarse precisamente la vida. De igual modo, el hombre es quizá en el mundo si no la única especie que trabaja, sí cuando menos aquella en la que la producción, la distribución y el consumo de los bienes han tomado tanta importancia y han recibido tantas formas y tan diferenciadas, pero la economía no es por ello una ciencia humana. Se dirá, quizá, que tiene recursos para definir las leyes interiores a los mecanismos de la producción (como la acumulación de capital o las relaciones entre la tasa de salarios y el precio de costo), a los comportamientos humanos y una representación que los funda (el interés, la búsqueda de la ganancia máxima, la tendencia al ahorro); pero al hacerlo, utiliza las representaciones como recurso de un funcionamiento (que pasa, en efecto, por una actividad humana explícita); en cambio, sólo habrá una ciencia del hombre si nos dirigimos a la manera en que los individuos o los grupos se representan a sus compañeros, en la producción o en el cambio, el modo en que se aclaran, ignoran o disfrazan este funcionamiento y la posición que ocupan en él, la forma en que se representan la sociedad en que se lleva a cabo, la manera en que se sienten integrados en ella o aislados, dependientes, sometidos o libres; el objeto de las ciencias humanas no es este hombre que, desde la aurora del mundo o el primer grito de su edad de oro, estaba consagrado al trabajo; es ese ser que, desde el interior de las formas de producción que dirigen toda su existencia, forma la representación de esas necesidades, de la sociedad por la cual, con la cual o contra la cual las satisface en tal medida que, a partir de allí, puede finalmente darse la representación de la economía misma. En cuanto al lenguaje es lo mismo: aunque el hombre sea en el mundo el único ser que habla no por ello es una ciencia humana conocer las mutaciones fonéticas, el parentesco de las lenguas, la ley de los deslizamientos semánticos; en cambio, se podrá hablar de ciencia humana una vez que se intente definir la manera en que los individuos o los grupos se representan las palabras, utilizan su forma y su sentido, componen sus discursos reales, muestran y ocultan en ellos lo que piensan, dicen, quizá sin saberlo, más o menos lo que no quieren, y en todo caso dejan una gran cantidad de huellas verbales de estos pensamientos, huellas que hay que descifrar y restituir en la medida de lo posible a su vivacidad representativa. El objeto de las ciencias humanas no es, pues, el lenguaje (hablado sin embargo por ellos solos), es ese ser que, desde el interior del lenguaje por el que está rodeado, se representa, al hablar, el sentido de los enunciados o de las proposiciones que enuncia y se da, por último, la representación del lenguaje mismo.

Vemos que las ciencias humanas no son un análisis de lo que el hombre es por naturaleza; sino más bien un análisis que se extiende entre aquello que el hombre 
es en su 'positividad' (ser vivo, trabajador, parlante) y aquello que permite a este mismo ser saber (o tratar de saber) lo que es la vida, en qué consisten la esencia del trabajo y sus leyes y de qué manera se puede hablar. Las ciencias humanas ocupan, pues, esta distancia que separa (no sin unirlas) la biología, la economía, la filología, de aquello que les da posibilidad en el ser mismo del hombre. Así, sería una equivocación el hacer de las ciencias humanas la prolongación, interiorizada en la especie humana, en su complejo organismo, en su conducta y en su conciencia, de los mecanismos biológicos; y no sería una equivocación menor el colocar entre las ciencias humanas a la ciencia de la economía y del lenguaje (cuya irreductibilidad a las ciencias humanas se manifiesta en el esfuerzo por constituir una economía y una linguiística puras).

Cuando Blanco reseña los aportes de la linguiística recuerda que las unidades aisladas, los signos, no significan nada, solamente «apuntan a»; precisa que la significación aparece embrionariamente en el sintagma, se amplía y se desarrolla con la frase, y se completa en el discurso ${ }^{1}$. Más allá del aporte de los modelos elaborados por la linguiística y de los gestos epistemológicos de la semiótica para diferenciarse de ella y adquirir su propia identidad, lo que está en juego cuando se habla de representación no es, pues, el signo como vehículo que la fijaría sino la significación como flujo de sentido. En suma, la construcción de representaciones que abre el ámbito de lo humano sólo puede operar como discurso. Según Valéry: «En verdad, no pensamos en una cosa, pensamos siempre de una cosa $a$ otra cosa». (1973, p. 1056)

En consecuencia, ninguna representación es «primera» o se da aislada respecto de otra u otras. Junto a una representación hay otra complementaria, contraria o contradictoria. Y junto a esa otra, otra. Y así sucesivamente. Es en la sintaxis de las representaciones, y en el juego semántico que las gradúa desde lo temático a lo icónico, donde se aprehende la significación. Sin embargo, cuando la semiótica actual estudia la emergencia de la significación a partir de lo sensible; o, cuando, en otros términos, explora la significación discursiva de la 'sensorialidad', resulta que las representaciones no son solo representaciones; juegan, a su vez, con verdaderas presencias de sentido.

Pues bien, ese paso de los órdenes sensoriales a los modos semióticos de lo sensible conduce a preguntar si acaso la significación aprehendida discursivamente no sería aquella placenta de sentido que da posibilidad de despliegue a lo específicamente humano. Entonces, la semiótica ni estaría incluida dentro de las ciencias humanas ni "se saldría» de su ámbito. Se situaría, más bien, de modo trascendental, en el ámbito de aquello que hace posible lo humano, a saber, el sentido hecho significación. 


\section{Los tres modelos y la crítica cognitiva de la representación}

Entonces, retomando el «mapa» de Foucault, el dominio de las ciencias del hombre estaría cubierto por tres regiones epistemológicas, subdivididas todas en el interior de sí mismas y entrecruzadas todas unas con otras; esas regiones se definen por la triple relación de las ciencias humanas en general con la biología, la economía y la filología. Así, podría admitirse que la "región psicológica» ha encontrado su lugar allí donde el ser vivo, en la prolongación de sus funciones, de sus esquemas neuromotores, de sus regulaciones fisiológicas, pero también en la suspensión que los interrumpe y los limita, se abre a la posibilidad de la representación; de la misma manera, la «región sociológica» habría encontrado su lugar allí donde el individuo que trabaja, produce y consume, se da la representación de la sociedad en la que ejerce esta actividad, de los grupos y de los individuos entre los cuales se reparte, de los imperativos, de las sanciones, de los ritos, de las fiestas y de las creencias que la sostienen o escanden; por último, en esta región en la que reinan las leyes y las formas de un lenguaje, pero donde a pesar de todo permanecen al borde de sí mismas, permitiendo al hombre hacer pasar por allí el juego de sus representaciones, allí nacen el estudio de las literaturas y de los mitos, el análisis de todas las manifestaciones orales y de todos los documentos escritos, en suma, el análisis de las huellas verbales que una cultura o un individuo puede dejar de sí mismo.

La vía semiótica de la significación discursiva se dio la tarea de ampliar este último ámbito hacia lo no-verbal, es decir, hacia las visiones significativas y las prácticas significantes. En ese trajín ha alternado dos miradas: una, hacia la significación en el discurso terminado; la otra, hacia la del discurso en acto. La primera vía es tributaria de los paradigmas del formalismo estructural tal como los describe Foucault. Así, Blanco remite a modelos como el recorrido generativo, el cuadrado semiótico, los esquemas y programas narrativos. Estos modelos exhiben hasta hoy un gran potencial heurístico y hermenéutico. En nuestro medio académico es lamentable su deficitaria difusión puesto que podrían permitir una articulación más consistente de los trabajos de investigación en ciencias humanas.

La segunda vía, del discurso en acto, es la que superó el paradigma estructural y algebraico y proyectó a la semiótica, decididamente, hacia el terreno fenomenológico y tensivo. Precisa Blanco que ya con las modalidades se habían sistematizado ámbitos de la comunicación humana (persuasión / interpretación; manipulación / sanción). Además, añade que las estructuras modales complejas permitieron abordar las pasiones puestas en discursos y, con ellas, la dimensión del afecto, de la emoción, del sentimiento, de la inclinación. En ese contexto, la semiótica recoge el axioma fenomenológico ("percibir es hacer presente algo por medio del 
cuerpo») y lo prolonga como axioma semiótico («enunciar es hacer presente algo por medio del lenguaje»). Cuerpo y lenguaje, en función de percibir y enunciar, se convierten en operadores de presencia, cualidad sensible por excelencia. Todo aquel universo del afecto se ve ahora anclado en lo sensible, en la sensación, en el sentir, en la estesis. Como vemos, las categorías semióticas, a su manera, han terminado creando su propia «biología». Pero lo más importante es que, en el horizonte del discurso en acto, se ha criticado y disuelto la centralidad epistemológica que, en autores como Foucault, ocupaba el concepto de representación.

En efecto, la lectura y recuperación de la fenomenología desde las ciencias cognitivas ha sido esencial para entender el fenómeno de la interpretación como 'enactuar' o 'hacer emerger' el sentido a partir de un trasfondo de comprensión. El conocimiento depende, pues, del hecho de estar en un mundo inseparable de nuestro cuerpo, de nuestro lenguaje y de nuestra historia social; en suma, de nuestra "corporización'2. En otros términos, la copertenencia cuerpo-mundo, expresada en todos los lenguajes existentes, es anterior a la constitución del yo como sujeto enfrentado con una realidad.

Con el verbo inglés to enact (que significa aproximadamente hacer emerger, suscitar), los 'cognitivistas', inspirados en mucha medida en Merleau-Ponty, enseñan que la acción encarnada es aquella acción según la cual el «mundo para sí» y el «sí» emergen juntos ${ }^{3}$.

El neologismo 'enacción' traduce el neologismo inglés enaction, derivado de enact, 'representar', en el sentido de 'desempeñar un papel, actuar'. De allí la forma 'enactuar', pues traducir 'actuar', 'representar' o 'poner en acto' llevaría a confusión. 'Hacer emerger' traduce la forma bring forth, a la vez asociada con el alemán hervorbringen, término de origen fenomenológico. (Varela, F; Thompson, E.; \& Rosch, E., 1997: 176) El principio de la enacción se basa, en lo esencial, en la solidaridad entre la sensación, la percepción, la experiencia y la acción. Gracias a esa solidaridad pueden emerger esquemas cognitivos. Este principio no es solamente una hipótesis teórica; es también un principio de método en cuanto sigue las enseñanzas de Merleau-Ponty que imponen no disociar jamás el sujeto y el mundo: así, a una concepción que distingue y trata separadamente el yo y el otro (el mundo) hay que oponer una concepción que pone en correlación e integra uno con otro el sí y el mundo para sí.

En el contexto de sustentación de la tesis de que el mundo y quien lo percibe se definen recíprocamente, el cognitivismo busca

«una vía media entre el Escila de la cognición como recuperación de un mundo externo predado (realismo) y el Caribdis de la cognición como 
A propósito de la SEMiótica y las CIENCIAS humanas (Comentario a la EXPOSICIÓn DE Desiderio Blanco)

proyección de un mundo interno pre-dado (idealismo). Ambos extremos se basan en el concepto central de representación: en el primer caso la representación se usa para recobrar lo externo; en el segundo se usa para proyectar lo interno. Nuestra intención es sortear esta geografía lógica de 'interno / externo' estudiando la cognición ni como recuperación ni como proyección, sino como acción corporizada. (...) Al hablar de 'corporizada' subrayamos: primero, que la cognición depende de las experiencias originadas en un cuerpo con diversas aptitudes sensorio-motrices; segundo, que estas aptitudes están encastradas en un contexto biológico, psicológico y cultural más amplio. (...) Al usar el término acción enfatizamos que los procesos motores y sensoriales, la percepción y la acción, son fundamentalmente inseparables en la cognición vivida. (...). Ahora podemos dar una definición preliminar de qué significa enacción. En síntesis, el enfoque enactivo consiste en dos cosas: 1) que la percepción es acción guiada perceptivamente; 2 ) que las estructuras cognitivas emergen de los modelos sensorio-motores recurrentes que permiten que la acción sea guiada perceptivamente». (Varela, F.; Thompson E.; \& Rosch, E., 1997: 202-203)

En consecuencia, la cognición como acción corporizada disuelve enactivamente la representación. Si la percepción es acción significativa, entonces, el ser inteligente no es tanto el que resuelve problemas como el que se las sabe ingeniar para ubicarse en un mundo compartido de significación. Por lo tanto, el 'contexto biológico, psicológico y cultural más amplio’ del que hablan los autores es un contexto significante sostenido por discursos; en suma, un ámbito semiótico que concierne -en términos de Foucault-a la 'positividad' propia de las ciencias humanas (a los conceptos en torno a los cuales se organizan, al tipo de racionalidad al que se refieren y por medio del cual tratan de constituirse como un saber); a su relación con la representación (y a ese hecho paradójico de que tomando su lugar sólo allí donde hay representación, se dirijan a las formas, los procesos inconscientes o, en todo caso, a los límites exteriores de la conciencia). La 'positividad' de las ciencias humanas, recuerda Foucault, se apoya simultáneamente sobre la transferencia de tres modelos distintos, con sus respectivas categorías, que se toman de los tres dominios de la biología, la economía y el estudio del lenguaje.

Sobre la superficie de proyección de la biología el hombre aparece como un ser que tiene funciones -que recibe estímulos (fisiológicos, pero también sociales, infrahumanos, culturales) y responde, se adapta, evoluciona, se somete a las exigencias del medio, compone con las modificaciones que impone, trata de borrar los desequilibrios, actúa según regularidades y tiene, en suma, las condiciones de existencia y la posibilidad de encontrar normas medias de ajuste que le permitan ejercer sus funciones. 
Sobre la superficie de proyección de la economía, el hombre aparece como un ser que tiene necesidades y deseos, que trata de satisfacerlos teniendo, pues, intereses, pensando en las ganancias, oponiéndose a otros hombres; en breve, aparece en una irreductible situación de conflicto; esquiva estos conflictos, huye de ellos o logra dominarlos, encontrar una solución que calme, cuando menos en un nivel y por un tiempo, la contradicción; instaura un conjunto de reglas que son, a la vez, limitaciones y vueltas del conflicto.

Sobre la superficie de proyección del lenguaje, las conductas del hombre aparecen como queriendo decir algo; sus menores gestos, hasta sus mecanismos involuntarios y sus fracasos, tienen un sentido; $y$ todo aquello que coloca en torno a él hecho de objetos, ritos, hábitos, discursos, todo el surco de huellas que deja tras de sí constituye un conjunto coherente y un sistema de signos.

Así, siempre según Foucault, estas tres parejas de la función y de la norma, del conflicto y de la regla, de la significación y del sistema, cubren sin residuos todo el dominio del conocimiento del hombre. De otro lado, para la semiótica del discurso en acto, en los tres casos, se trataría de un actante que habitaría un espacio tensivo. Hay aquí algo de suma importancia, a saber, que el ' $y o$ ' semiótico no se reduce al 'yo' linguístico. Si admitimos que el 'yo' semiótico es un 'yo' sensible, afectado, con frecuencia atónito, es decir, emocionado por los éxtasis que lo asaltan, un 'yo' oscilante más bien que 'identitario', podremos concluir que el 'yo' semiótico es básicamente un 'yo' mítico: habita un espacio tensivo en cuyo centro se asocian la intensidad y la profundidad; como sujeto, se esfuerza, igual que todo ser viviente, por hacer ese nicho habitable; por ajustar y regular las tensiones arreglando las morfologías que lo condicionan. Norma, regla y sistema, por un lado; función, conflicto y significación, por el otro; no son otra cosa que formas virtuales y actuales mediante las cuales se articula y 'racionaliza' ese exceso del afecto sobre el concepto.

Esta perspectiva fenomenológica de la semiótica, desde otra posición, le da la razón a Foucault: no hay que creer que cada una de estas parejas de conceptos permanece localizada en la superficie de proyección en la que pudo aparecer: la función y la norma no son conceptos psicológicos ni exclusivamente tales; el conflicto y la regla no tienen una aplicación limitada solo al dominio sociológico; la significación y el sistema no valen únicamente para los fenómenos más o menos aparentes del lenguaje. Todas estas categorías son tomadas de nuevo en el volumen común de las ciencias humanas, valen en cada una de las regiones que comprende: de allí que, con frecuencia, sea difícil fijar los límites no solamente entre los objetos, sino también entre los métodos propios de la psicología, la sociología y el análisis de la literatura y de los mitos. Sin embargo, puede decirse, de manera global, que la psicología es fundamentalmente un estudio del hombre en términos de funciones y 
de normas (que pueden interpretarse, de modo secundario, a partir de los conflictos y las significaciones, las reglas y los sistemas); la sociología es fundamentalmente un estudio del hombre en términos de reglas y conflictos (pero éstos pueden ser interpretados y sin cesar han sido interpretados secundariamente sea a partir de las funciones, como si fueran individuos orgánicamente ligados a sí mismos; sea a partir de sistemas de significaciones, como si fueran textos escritos o hablados); por último, el estudio de las literaturas y de los mitos remite esencialmente a un análisis de las significaciones y de los sistemas significativos, pero se sabe muy bien que se puede retomar éstos en términos de coherencia funcional o de conflictos y de reglas.

Así, todas las ciencias humanas se entrecruzan y pueden interpretarse siempre unas a otras, sus fronteras se borran, las disciplinas intermediarias y mixtas se multiplican indefinidamente y su objeto propio acaba por disolverse. Pero sea la que fuera la naturaleza del análisis y el dominio al que se aplica, se tiene un criterio formal para saber qué es lo que pertenece al nivel de la psicología, de la sociología o del análisis de los lenguajes: es la elección del modelo fundamental y la posición de los modelos secundarios lo que permite saber en qué momento se 'psicologiza' o se 'sociologiza' en el estudio de las literaturas y de los mitos, en qué momento se hace, en psicología, un desciframiento de textos o un análisis sociológico; y, a la inversa, en qué momento se comienza a hacer 'psicosemiótica' o 'sociosemiótica'. Pero esta superposición de varios modelos no es una falta de método. Existe tal falta cuando los modelos no se ordenan y articulan explícitamente unos sobre otros. Cuando no se jerarquizan. Recuerda Blanco que la interdisciplinariedad no es ni copia ni traslado sin más ni más; aclara que las incorporaciones requieren un trabajo creativo de adaptación a la metodología y al «objeto» de la disciplina de acogida; de lo contrario, se incurre en un eclecticismo estéril y pernicioso.

Entonces, cada disciplina tiene que mantener el rigor de su "proyecto científico». Blanco remite al modo como Fontanille rescata elementos del psicoanálisis para llevarlos al modelo semiótico de la enunciación en acto. Foucault, por su lado, remite a la admirable precisión con que se ha podido llevar el estudio de las mitologías indoeuropeas utilizando, sobre la base de un análisis de los significantes y las significaciones, el modelo sociológico. En cambio, recuerda a qué trivialidades sincréticas ha llevado siempre la mediocre tentativa de fundar una psicología llamada «Clínica».

En fin, volviendo a nuestro asunto, notaremos que, en la perspectiva de la linguiística, el interés recae exclusivamente en los sistemas de valor que constituyen las lenguas. Por otro lado, la semiología sólo se interesa por los signos aislables y bien formados. Por lo tanto, ni a ésta ni a aquella les llama la atención la llamada sustancia, menos aún el paso de la sustancia a la forma. Pero, para una semiótica del discurso en acto, en la que se juega sin cesar la «escena primitiva» de la 
significación, es decir, la emergencia del sentido a partir de lo sensible, el planteamiento 'propioceptivo' y 'enactivo' se vuelve fundamental.

Por cierto que la semiótica del discurso en acto le da su lugar a la perspectiva de la representación, pero situándola en la dimensión figurativa e icónica de los discursos. Mientras tanto, la construcción epistemológica del discurso en acto, adopta decididamente la perspectiva de la enacción que someramente hemos expuesto. Cabe recalcar que la dimensión propia del yo semiótico es la del afecto; esto es, la del estado o 'temperatura' de la relación sensible entre el sujeto y su entorno. Expresión y contenido, planos del lenguaje, están 'enactuados'. No es que alguien «tenga contenidos» en la mente y luego «los exprese». Tampoco cabe pensar, a la inversa, que una vez manifestadas determinadas expresiones «les atribuimos contenidos $\rangle^{5}$.

\section{Praxis enunciativa e historicidad}

Señala Foucault que quizá la historia no tenga un lugar entre las ciencias humanas ni al lado de ellas: es probable que mantenga con todas ellas una relación extraña, indefinida, imborrable y más fundamental de lo que sería una relación de vecindad en un espacio común. Sea como fuere, la disposición de la historia en el espacio epistemológico tiene una gran importancia para su relación con las ciencias humanas. El hombre histórico -de acuerdo con Foucault- es el hombre vivo, que trabaja y habla. A partir de ahí, en la episteme moderna, todo contenido de la historia, sea cual fuere, depende de la psicología, de la sociología o de las ciencias del lenguaje. Pero, precisamente porque el ser humano se ha convertido en histórico de un cabo a otro, ninguno de los contenidos analizados por las ciencias humanas puede permanecer estable en sí mismo ni escapar al movimiento de la historia.

Ahora bien, en la perspectiva semiótica del discurso en acto, a partir de la centralidad de la enunciación, hay que admitir que la historia es un hecho sólo en el sentido en el que es un hecho un relato. En consecuencia, el «movimiento de la historia» es inconcebible e imperceptible sin una praxis enunciativa. En términos caros a Foucault, cuesta imaginar la historia sin documentos. La historia no 'es', más bien 'se dice'. Lo que se da en el horizonte de lo humano es esa experiencia que Heidegger ha denominado Ereignis, traducida por Garrido como «acaecimiento apropiador», pretendidamente explicado por la teoría semiótica fenomenológica desde la propioceptividad de un cuerpo sensible. Lo más propio del hombre converge ahí, 'asintóticamente', con lo más propio del ser. Tiempo y ser se dan en la existencia. Pero la $y$ (en tiempo y ser) aludiría al acontecimiento apropiador en el que sólo cabe la predicación interna, tautológica (o tautegórica, como diría Cassirer). En efecto, el predicado que mejor cuadra tanto a ser como a tiempo es el impersonal 
«hay» $\mathbf{0}$ «se da» (gibt en alemán); mientras tanto, del Ereignis no se puede decir ni que «es» ni que «se da», sino sólo que ereignet, lo cual se traduce alternativamente: «el acontecimiento acontece / la apropiación apropia», o también que «el acontecimiento apropiador acontece apropiadoramente». Ahora bien, el acontecimiento apropiador del ser tiempo se vive en su relación con el lenguaje. Nos vamos apropiando de algo que inicialmente puede antojársenos ajeno, pero que luego se va haciendo gradual y consustancialmente lo más propio, sin que podamos precisar hasta qué punto somos nosotros quienes nos estamos apropiando del lenguaje o es el lenguaje quien nos expropia o enajena ${ }^{6}$.

Entonces, ni el ser se deja apelar como algo temporal ni el tiempo se deja apelar como ente. El ser no es una cosa real y concreta, y por tanto nada temporal, pero es determinado como presencia por el tiempo. Por otro lado, el tiempo no es ninguna cosa real y concreta, y por tanto nada ente, pero permanece constante en su pasar, sin ser él mismo algo temporal como lo ente en el tiempo. El análisis ontológico del hombre como ente en el tiempo, constitutivamente mundano y moribundo, anclado en la finitud y que se interroga por el ser es previo al análisis ontológico del ser. Dentro de la lógica y la retórica del don, del darse, el ser es vestido con ropaje de destino y la donación del tiempo es dramatizada con el atributo nombrado por el verbo alemán reichen ('tender', 'extender', 'alcanzar', 'ofrendar') que connota no sólo la distancia espacio-temporal (extensidad) sino también el influjo de un poder o autoridad (intensidad) ${ }^{7}$.

En consecuencia, desde la constancia del paso del tiempo, reina y habla el ser. Ese modo de hablar el ser, en la existencia humana, se llama historia. Por eso el ser de la existencia humana es un ser histórico. La historicidad, es decir, la temporalidad, significa ser en un sentido más originario que el estar ahí dado que la ciencia natural trata de conocer. Hay una razón histórica porque la existencia humana es temporal e histórica. Hay una historia mundial porque esa existencia temporal del hombre 'tiene un mundo'. Hay cronología porque la existencia histórica del hombre es tiempo ${ }^{8}$.

Pues bien, en ese contexto, «nadie habla por primera vez». Como precisa Blanco, no hay enunciador que enuncie aisladamente, desconectado de otros enunciadores; todo enunciador es un actante societal, dispone de una memoria y habla en medio de otras hablas. Por lo tanto, sus actos de enunciación se inscriben en ese funcionamiento propio del lenguaje que está más allá o más acá de él como individuo. Funcionamiento éste creador y cohesivo. En consecuencia, en la perspectiva de nuestra reflexión, no hay ciencia si no se asumen discursos. Las ciencias son discursos, y todo discurso requiere, para existir, de actos de enunciación. 
Ese funcionamiento general del lenguaje es el de la praxis enunciativa. Ésta realiza magnitudes semióticas en un campo 'de conciencia' dado: las hace presentes. Pero nuestra condición temporal hace que las cosas presentes fluyan hacia el horizonte de la ausencia. La dinámica del olvido hace que eso que ya no está presente se extinga en la ausencia. No obstante, la memoria está hecha de cosas que no están presentes pero tampoco están ausentes. Y el recuerdo, de cosas que no están ausentes y van a estar presentes.

Esas cosas son magnitudes semióticas. Por consiguiente, la praxis enunciativa hace posible la aparición y la desaparición de los enunciados y las formas semióticas en el campo del discurso. La instancia de discurso existe en el devenir temporal mismo de esa praxis. Hay varios pasajes en los que Foucault parece estar hablando de la praxis enunciativa, quizá el más representativo aquel en el que señala que la cadena significante por la que se constituye la experiencia única del individuo es perpendicular al sistema formal a partir del cual se constituyen las significaciones de una cultura: en cada instante la estructura propia de la experiencia individual encuentra en los sistemas de la sociedad un cierto número de posibles elecciones (y de posibilidades excluidas); a la inversa, las estructuras sociales encuentran en cada uno de sus puntos de elección un cierto número de individuos posibles (y de otros que no lo son) $)^{9}$.

Blanco, mientras tanto, culmina su exposición explicando que la praxis enunciativa capta las unidades y los enunciados en su estado virtual (en cuanto entidades de un sistema); las actualiza (en cuanto seres de lenguaje y de discurso); las realiza (en cuanto expresiones); y las potencializa (en cuanto productos del uso). En nuestra existencia temporal e histórica, tomamos posición entre los diferentes modos de existencia de la significación y desde ahí nos conectamos y comunicamos con nosotros mismos, con el mundo, con los otros. En efecto, la significación existe de modo virtual en sistemas, de modo actual en discurso, de modo real en textos, de modo potencial, en memorias...de otros discursos.

\section{Reflexión final}

Quizá la semiótica del discurso en acto sea ese modo de pensamiento evocado por Foucault como desconocido aún (1968: 329). Modo de pensamiento que permitiría reflexionar a la vez, sin discontinuidad ni contradicción, el ser del hombre y el ser del lenguaje; además de conjurar, con las mayores precauciones, todo aquello que puede significar un retorno ingenuo a la teoría clásica del discurso, retorno cuya tentación es mayor mientras más desarmados estamos para pensar el ser centelleante pero abrupto del lenguaje. La vieja teoría de la representación nos sigue ofreciendo un lugar en el que este ser podría alojarse y disolverse en un puro funcionamiento. Por 
eso es posible que se excluya para siempre el derecho de pensar a la vez el ser del lenguaje y el ser del hombre. Advierte Foucault que la única cosa que sabemos por el momento con toda certeza es que en la cultura occidental jamás han podido coexistir y articularse uno en otro el ser del hombre y el ser del lenguaje. Su incompatibilidad ha sido uno de los rasgos fundamentales de nuestro pensamiento. A partir de reflexiones como la de Desiderio Blanco, que aproximan el ser del hombre (ciencias humanas) y el ser del lenguaje (semiótica); que, además, fusionan sin reparos existencia y significación, empiezo a presentir que una hermenéutica semiótica del discurso en acto, fiel a las peripecias existenciales del sentido hecho significación, podría estar en condiciones de vislumbrar, a contracorriente, una posible convergencia.

\section{Notas}

1 Previamente ha señalado las dos direcciones de la semiótica moderna: la semiología, cuyo objeto de estudio es el signo y cuyo método es descriptivo-taxonómico; y la semiótica, cuyo objeto primordial es la significación, que sólo puede encontrarse en el discurso, es decir, por debajo de los signos o más allá de los signos; y cuyo método es inmanente y generativo.

2 «Nuestro cuerpo es ese extraño objeto que utiliza sus propias partes como simbólica general del mundo y por el cual, en consecuencia, podemos 'frecuentar' ese mundo, 'comprenderlo' y encontrarle una significación». Merleau-Ponty, M; 1985: 271. La conformación simbólica 'comienza' pues en el propio cuerpo. Nuestros cuerpos, en la línea trazada por Merleau-Ponty, no deben ser vistos sólo como estructuras físicas, contexto y ámbito de los mecanismos cognitivos; sino, esencialmente, como estructuras 'experienciales' vividas, es decir, como 'externos' e 'internos', como biológicos y fenomenológicos. Es obvio que ambos aspectos de la corporalidad no se oponen sino que, por el contrario, circulamos continuamente de un aspecto al otro.

3 Una detallada explicación de este concepto en: Varela, F.,Thompson, E., \& Rosch, E., 1997: 174-247. La especificación de lo que es un medio ambiente, enseñan los autores, no se puede separar de lo que son y hacen los organismos. Se trata de una relación de especificación mutua o codeterminación. Hay que desmitificar, entonces, la concepción del medio ambiente como una estructura impuesta sobre los seres vivientes desde el exterior y comenzar a pensarlo como creación de esos seres. El medio ambiente no es un proceso autónomo sino un reflejo de la biología de la especie. Así como no hay organismo sin medio ambiente, no hay medio ambiente sin organismo. La percepción es acción guiada perceptivamente y las estructuras cognitivas emergen de los modelos sensorio-motores recurrentes que permiten que la acción sea guiada por la percepción. En síntesis, este enfoque sustenta que la cognición no es representación sino acción corporizada, y que el mundo que conocemos no es pre-dado, sino que se enactúa a través de nuestra historia de acoplamiento estructural.

4 Los autores, refiriéndose a la filosofía budista, afirman que la enacción puede ser objeto de una experiencia concreta: la práctica de la atención, definida como presencia del espíritu (de sî) a la experiencia, da acceso directo a esa emergencia interactiva del sí y del mundo. Y esa presencia puede, incluso, ser descrita como sincronización de la atención y del flujo del cuerpo y del espíritu. Asunto de tempo, de acuerdo a Zilberberg. Por último, la existencia de la enacción no sólo es verificable por experiencia íntima: sus consecuencias pueden ser 
A propósito de la SEMiótica y las CIENCIAS humanas (Comentario a la EXPOSICIÓn de Desiderio BlanCo)

objeto de observaciones clínicas, y su despliegue es particularmente sorprendente en la literatura y en las artes figurativas en general

5 Entonces, los dos universos semióticos (expresión / contenido) son reunidos ipso facto por la toma de posición de un cuerpo propio. Las propiedades de ese cuerpo propio, que se pueden designar globalmente con el término propioceptividad, pertenecen a la vez al universo interoceptivo (contenido) y al universo exteroceptivo (expresión). La reunión de los dos universos, con vistas a hacerlos significar en conjunto, se hace posible por el tercero, y en particular por el hecho de que pertenece a la vez a los otros dos.

El cuerpo propio hace de esos dos universos los dos planos de un lenguaje. Que esa operación desemboque en una presuposición recíproca resulta de poco interés frente a esta última proposición: el cuerpo sensible está en el corazón de la función semiótica, el cuerpo propio es el operador de la reunión de los dos planos de los lenguajes. Esta simple fórmula: la semiosis es propioceptiva tiene numerosas repercusiones. La más evidente, tiende a esta nueva proposición: si la función semiótica es propioceptiva más que lógica, entonces la significación es más afectiva, emotiva, pasional, que conceptual o cognitiva (Fontanille, J. 2001: 40). Nosotros podemos colegir de este planteamiento que, n la significación, hay un exceso de lo mítico sobre lo lógico.

6 Introducción de Manuel Garrido en Heidegger, 2003: 9-18.

7 Cabe notar que la raíz rec es la misma que la del latín rex, que figura en los términos españoles régimen o región o en el alemán Reich.

8 Gadamer, H.-G. 1998: 39.

9 Foucault, M; 1968: 369.

\section{Referencias bibliográficas}

FONTANILLE, Jacques (2001): Semiótica del discurso. Universidad de Lima / Fondo de Cultura Económica, Lima.

FOUCAULT, Michel (1968): Las palabras y las cosas. Una arqueología de las ciencias humanas. Siglo XXI Editores, México.

GADAMER, Hans-George (1998): Verdad y método II. Ediciones Sígueme, Salamanca.

HEIDEGGER, Martin (2003): Tiempo y ser. Tecnos, Madrid.

Merleau-Ponty (1985): Fenomenología de la percepción. Origen/Planeta, México.

VALÉRY, Paul (1973): Cahiers. T.1. Gallimard. Coll. La Pléiade, Paris.

VARELA, Francisco; THOMPSON, Evan \&, ROSCH, Eleanor (1997): De cuerpo presente.

Gedisa, Barcelona. 